\title{
O ESPAÇO LITERÁRIO DA DIÁSPORA AFRICANA: REFLEXÕES TEÓRICAS
}

\author{
Roland Walter ${ }^{1}$
}

\begin{abstract}
Resumo: Este ensaio focaliza questões teóricas da abordagem comparativa das literaturas que constituem o espaço literário da diáspora negra. Ele parte da hipótese de que a análise comparativa e interdisciplinar deve interrelacionar o "inconsciente político", o "inconsciente cultural" e o "inconsciente ecológico" que caracterizam os textos. Neste sentido, entende-se o texto literário como cronotopo e situado num cronotopo imbuído do fantasma recalcado das violências e brutalizações, o qual volta em resposta à Verleugnung, fazendo sentir sua presença tanto no nível da enunciação textual quanto no da experiência vivida. Com relação aos afrodescendentes, este espaço-tempo (literário/existencial) é multidimensional: uma encruzilhada diaspórica onde culturas e epistemes se encontram e transculturam. Isto implica num dos assuntos principais problematizado neste ensaio: como podemos analisar os fluxos dinâmicos desta encruzilhada?

Palavras-Chave: Literatura/teoria afro-diaspórica; Memória; Transculturação; Inconsciente político/cultural/ecológico.
\end{abstract}

\begin{abstract}
This essay focuses on how to theoretically analyze the literatures that compose the space of the Black Diaspora. It is based on the hypothesis that a comparative and interdisciplinary analysis should connect the 'political unconscious', the 'cultural unconscious' and the 'ecological unconscious' that characterize the texts. In this sense, the literary text is understood as a cronotope and as situated in a cronotope imbued with the repressed violences and brutalizations that come back in response to the Verleugnung, making their presence felt at the level of both textual enunciation and lived experience. With reference to black people in the Diaspora, this literary and existential time-space is multidimensional: a diasporic crossroads where cultures and epistemes meet and transculturate. This implies one of the principal issues problematized in this essay: how can we analyze the dynamic fluxes of this diasporic crossroads?

Keywords: Black literature/theory; Diaspora; Memory; Transculturation; Political/cultural/ecological unconscious.
\end{abstract}

1 Professor Assosciado da Universidade Federal de Pernambuco (UFPE); Docente do Programa de Pós-Graduação em Letras e Linguística (PPGLL), área de Teoria da Literatura; Pesquisador de Produtividade PQ/CNPq. Endereço eletrônico: rolandgwalter@yahoo. com. 


\section{INTRODUÇÃO}

Como analisar de maneira comparativa as literaturas que constituem o espaço diaspórico dos afrodescendentes pan-americanos? Quais os instrumentos teóricos a nossa disposição para examinar e problematizar textos (escritos em diversos idiomas) de escritores que compartilham (em diferentes contextos socioculturais) um conjunto de experiências em comum: dominação e resistência, escravidão e emancipação, a busca de liberdade e a luta contra o racismo? Como compreender semelhanças e diferenças entre e dentro das diversas comunidades negras nas Américas?

Gostaria de basear os pensamentos que seguem na seguinte hipótese: para compreender e analisar as literaturas que compõem o espaço diaspórico dos afrodescendentes nas Américas no seu processo histórico deverse-ia inter-relacionar o "inconsciente político" (Jameson), o "inconsciente cultural" (Bourdieu) e o "inconsciente ecológico" (Walter) que imbuem os textos; ou seja, dever-se-ia entender o texto como cronotopo e situado num cronotopo impregnado com o fantasma das violências e brutalizações recalcado, o qual volta em resposta à Verleugnung, fazendo sentir sua presença tanto no nível da enunciação textual quanto no da experiência vivida. Com relação aos afrodescendentes, este espaço-tempo (literário/existencial) é multidimensional: uma encruzilhada diaspórica onde culturas e epistemes se encontram e transculturam.

\section{DIÁSPORA E IDENTIDADE}

A palavra "diáspora" vem do verbo grego speiro que significa "semear" e "disseminar". Tradicionalmente, a diáspora designou raízes, terra (ponto de origem atual ou imaginado) e parentesco (comunidade local e grupo globalmente dispersado): a perda do país natal e o desejo da volta. Atualmente, com o aumento de culturas migratórias e hifenizadas, o conceito significa menos um estado/vida entre lugares geográficos, conotando, de maneira mais abrangente (e talvez de forma menos concreta), um vaivém entre lugares, tempos, culturas e epistemes ${ }^{2}$.

2 Estas dimensões da identidade diaspórica são questionadas enquanto possíveis critérios para a definição do termo (Brubaker, 2005, p. 5-7; Peeren, 2007). Enquanto alguns, como Safran (1991), enfatizam a importância de raízes, outros, como Hall (1993), Gilroy (1997), entre outros, destacam o hibridismo das comunidades diaspóricas. James Clifford (1997) problematiza a diáspora enquanto ligação tensiva entre raízes e rizomas.

10 Número temático: Literatura, cultura e memória negra. A Cor das Letras - UEFS, n. 12, 2011 
Diáspora, portanto, é um termo que indica: um grupo de pessoas, um estado histórico do Dasein, um entre-lugar geográfico e temporal. A palavra sugere redes de relações reais ou imaginadas entre povos dispersos cuja comunidade é sustentada por diversos contatos e comunicações que incluem família, negócio, viagem, cultura compartilhada e mídia eletrônica, entre outros. Ao ligar as comunidades de uma população dispersa em e entre diferentes nações e/ou regiões, a diáspora constitui uma das formas transnacionais par excellence. Isto significa que ela não necessariamente subverte o Estado-nação, mas o heterogeneiza. Neste sentido, sua relação com as normas do Estado-nação e as formações identitárias nativistas é caracterizada por tensão e/ou ambiguidade. A existência diaspórica, portanto, designa um entre-lugar caracterizado por desterritorialização e reterritorialização, bem como pela implícita tensão entre a vida aqui e a memória e o desejo pelo lá. Neste sentido, os que vivem na diáspora compartilham uma dupla se não múltipla consciência e perspectiva, caracterizadas por um diálogo difícil entre vários costumes e maneiras de pensar e agir. Membros de uma diáspora habitam línguas, histórias e identidades que mudam constantemente. São tradutores culturais cujas passagens fronteiriças minam limites estáveis e fixos, que reescrevem o passado e as tradições num processo de reinserção contínua; um recontar que mina autenticidades e problematiza os interstícios sombreados pelo discurso oficial. A casa-lar que a diáspora constrói, além de ser um entre-lugar, existe também em um entretempo: entre um passado perdido, um presente não-integrado e um futuro desejado e diferido. Daí resulta "o discurso [...] descentrado", assim como as "narrativas bifrontes e até [...] esquizofrênicas" dos seus moradores (CORNEJO POLAR, 2000, p. 304). Por muitos destes moradores diaspóricos sua casa-lar, além de ser um entre-lugar, muitas vezes se torna um translugar. Em distinção ao não-lugar de Marc Augé (1992), gostaria de chamar a encruzilhada diaspórica um trans-lugar, por ser construído por diferentes elementos culturais em travessia. Uma travessia de vários e diferentes tipos de encontro: mescla, embate, justaposição, sobreposição e diversos tipos de apropriação. Esta dança de passos contrapontísticos no hífen da transcultura liga múltiplos processos de continuidade e ruptura em complementaridade contraditória.

A existência entre lugares e epistemes - que, segundo Bhabha, Hall e Said, entre outros, facilita a compreensão crítica e a originalidade discursiva porque qualquer tipo de desterritorialização e mobilidade faz com que o escritor abandone posições fixas de identidade e ideologias homogenei- 
zadoras e nacionalistas - está sempre inscrita nas redes de relações de poder locais e globais. Formações transnacionais são sempre interpoladas pelas políticas locais e vice-versa (Mignolo, 2003). O resultado é que as identidades e comunidades diaspóricas são heterogêneas, fluidas e fragmentadas entre a perda e o ganho, a expropriação e a potencialização, a exclusão e a inclusão. Devido às diferentes circunstâncias em diversos contextos socioculturais, é crucial lembrar que a análise intercultural deveria estar atenta à especificidade da formação histórica e do lugar geográfico da diáspora e de suas características específicas: embora exista uma diáspora negra nas Américas, a materialidade do dia-a-dia que a constitui é diferente no Brasil, na Venezuela, em Cuba, nos Estados Unidos e no Canadá, entre outros. A diáspora afrodescendente das Américas pode ser entendida, portanto, como espaço diaspórico constituído por diversos lugares e comunidades heterogêneos: uma encruzilhada mediada por uma transcultura heterotópica onde existem lares e desabrigos entre lugares e mares. Viver nesta encruzilhada fronteiriça, diaspórica, transnacional e transcultural, portanto, envolve negociações e significa que a subjetividade evocada nesta existência é constituída por múltiplas trajetórias históricas, lingüísticas, étnico-raciais e culturais.

O conceito da diáspora contemporânea oferece uma crítica dos discursos de origens fixas; no entanto, leva em conta aqueles que ficaram para trás ou encontraram raízes fixas ou rizomáticas em um lugar ou entre lugares. A pátria enquanto autêntico lugar de pertença cultural nostalgicamente lembrado é suplementado pelo que Avtar Brah (1996, p. 180) chama de um desejo por um lar (que difere de um desejo por uma pátria). Esta distinção é importante no sentido de que nem toda diáspora sustenta uma ideologia de volta, mesmo que as condições de vida dificultem o sentir-se em casa no novo país - volta esta que, no caso da diáspora africana, era impossível. Desta forma, a teorização na/da encruzilhada diaspórica transcultural pode fornecer uma compreensão não essencialista de formações identitárias e de cidadanias interculturais e transnacionais.

Ideias sobre a diasporização dos negros remontam às primeiras escritas dos africanos escravizados e afrodescendentes. Desde o século dezoito escritores e pensadores negros, como por exemplo, Phillis Wheatley, Olaudah Equiano, Harriet Jacobs, Harriet E. Wilson, Maria Firmina dos Reis, William Wells Brown, Frederick Douglass, Martin A. Delany, Frank J. Webb, Ida B. Wells, Antonio Pereira Rebouças, Alexander Crummell, Edward Wilmot Blyden e João de Cruz e Souza, entre outros, focalizaram diversos aspectos da experiência negra durante a escravidão e o sistema de plantação, como

12 Número temático: Literatura, cultura e memória negra. A Cor das Letras - UEFS, n. 12, 2011 
também seus efeitos nefastos pós-abolição dentro de um contínuo e violento processo de estratificação social. No século XX, tanto W. E. B. Du Bois quanto Marcus Garvey e os integrantes do movimento da negritude, entre outros, em sua diferença, enfatizaram algum tipo de essência racial como característica principal da diáspora negra: a (com)unidade negra se fundamenta em "blackness" ${ }^{3}$. A implícita homogeneização de comunidades negras - divididas internamente por classe, origem, idade, gênero, experiência e consciência - sob a ideia e definição de uma única e semelhante história/identidade/comunidade foi questionada e desconstruída a partir da década sessenta, por, entre outros, George Shepperson e Joseph Harris. Enquanto que para Shepperson $(1962,1976)$ o conceito da diáspora negra é baseado na escravidão e na migração como também nas consequências destes processos históricos sobre a vida dos africanos e afrodescendentes, Harris (1993, p. 3-4) define a diáspora africana de seguinte forma:

a dispersão global (de maneira voluntaria ou involuntária) dos africanos durante toda a história; a emergência de uma identidade cultural no exterior que é baseada na origem e condição social; e a volta psicológica ou física para a terra natal, a África. Assim, a diáspora negra assume o caráter de um fenômeno dinâmico, contínuo e complexo que abrange tempo, geografia, classe e gênero ${ }^{4}$.

Em O Atlântico Negro, Paul Gilroy argumenta que se deve mudar a autopercepção paradigmática da cultura negra da ideia de raça para aquela de diáspora. Nas páginas finais e no seu livro seguinte, Against Race (2000, p. 123), ele defende que a ideia de raça é baseada numa relação fixa entre pessoas e seu lugar de origem, enquanto os estudos da cultura do Atlântico Negro - espaço que Gilroy (2001, p. 38) percebe como uma "estrutura rizomórfica e fractal da formação transcultural e internacional" - focalizam precisamente a dissolução desta ligação e suas consequências. A ideia da diáspora, segundo Gilroy, oferece uma alternativa ao pensamento da origem única e do pertencimento cultural estável. O trabalho de Gilroy sobre o Atlântico Negro revela a "diáspora" como uma formação que permite diálogo mediante disjunção e diferença; um espaço que possibilita o nascimento de uma coletividade.

Stuart Hall (2000, p. 31), na sua definição da diáspora africana, confirma que

3 Para uma crítica desta falácia, ver Appiah (1992).

4 As traduções são de minha autoria. 
diáspora não nos remete a estas tribos espalhadas cujas identidades somente podem ser obtidas em relação a uma terra sagrada onde têm que voltar custe o que custar [...]. Isto é a velha forma imperializadora e hegemonizadora de "etnicidade". [...] A meu ver, a experiência diaspórica é definida, não por essência ou pureza, mas pelo reconhecimento de uma heterogeneidade e diversidade necessária; por uma concepção de "identidade" que vive não apesar, mas com e através da diferença; por hibridismo. As identidades diaspóricas são aquelas que constantemente se produzem e reproduzem de novo por meio de transformação e diferença [ênfase no original].

O mar e a terra, os que ficaram para trás e os que foram escravizados, os que ficaram nas plantações e os que fugiram, os que se rebelaram e os que colaboraram: a literatura da diáspora africana nos demonstra que o que importa, no entendimento e na análise do holocausto do Atlântico Negro, é a inter-relação entre os seus elementos e as suas cores constituintes. Já que a experiência dos afrodescendentes nos diversos contextos culturais e nacionais da diáspora negra difere, deveria se examinar a desterritorialização do entre-lugar diaspórico em relação com as implícitas tentativas de reterritorialização, ou seja, como os diversos locais são produzidos e quais são as suas características no espaço da disseminação.

Inscrita na ideia da diáspora está a noção da fronteira. Enquanto linhas divisórias da diferenciação espacial, temporal e cultural, fronteiras distanciam a identidade interna da alteridade externa e, enquanto entreespaços compartilhados, ligam-nas. Estabelecem hierarquias entre o interior e o exterior, assim como dentro destes. Desse modo, elas contêm as diversas formas de diferença ao transformar os sujeitos em estrangeiros e/ou ilegais (perigosos), fora do real inteligível, normal e/ou humano. Simultaneamente, as fronteiras e seus espaços intervalares são reproduzidos e re-imaginados no processo da resistência à subalternização e marginalização. As fronteiras e os espaços fronteiriços, portanto, constituem o terreno onde as identidades são vividas e imaginadas, numa interação tensiva de estase cultural (diferença enquanto separação) e transgressão cultural (diversidade enquanto relação). Fronteiras conotam estase cultural ao canalizar a identidade cultural para epistemes nacionalmente identificadas enquanto a transgressão destas fronteiras revela espaços intersticiais onde as diferenças culturais são traduzidas para relações interculturais de pluralidade simbiótica e/ou sintética. Neste sentido, fronteiras e espaços fronteiriços são entidades materiais e símbolos que constituem lugares tanto de poder do Estado repressivo e normalizador, quanto de transgressivas funções e práticas transnacionais e transculturais. Portanto, para poder mapear os 
fluxos culturais disjuntivos e conjuntivos que passam por e/ou se embatem nas fronteiras geográficas, psicológicas, físicas e culturais, o crítico também deveria se colocar acima das fronteiras, não trabalhando de maneira homogênea dentro, mas de maneira heterogênea desde uma variedade de fronteiras interdisciplinares. A fronteira e seus entre-espaços, portanto, são conceitualizados tanto como construções político-econômicas, socioculturais, geográficas, psíquicas e metafóricas, quanto como categorias analíticas e posições epistemológicas.

Os conceitos da diáspora e da fronteira referem-se ao tema da mobilidade (física ou imaginada): o entrelaçamento da desterritorialização com a reterritorialização dentro ou entre espaços onde as posições de gênero, classe, raça, etnicidade, sexualidade e idade dos sujeitos complementam-se de maneira contraditória; isto é, muitas vezes são simultaneamente enraizadas e dispersas, se cruzam ou são justapostas, contestadas, afirmadas e negadas em consequência de uma confluência heterotópica de processos econômicos, políticos, históricos, culturais e identitários.

O espaço da diáspora africana é uma das zonas de contato interamericanas par excellence. Desde a época da escravatura, colonização e do sistema de plantação até a presente fase neoliberal da globalização/mundialização, este espaço tem sido a cena da mestiçagem de culturas e identidades. Dispersão, desterritorialização e expropriação são aspectos fundamentais da transculturação africana. Na revelação e problematização destes aspectos, os escritores negros indicam uma história apocalíptica uma história que fracassou no contexto da escravidão e das suas consequências - como fonte da desorientação e/ou do dano psíquico dos seus personagens. A escritora afro-canadense Dionne Brand (2002, p. 18, 29, 5), cujos personagens ficcionais fazem caminhadas esquizofrênicas dentro e através dos interstícios úmidos e famintos deste mundo, argumenta que "viver na Diáspora negra é [...] como viver uma ficção - uma criação de impérios e também uma autocriação. É uma existência ao mesmo tempo fora e dentro de si mesmo" caracterizada por um "esquema cognitivo" de "cativeiro". Preso numa origem enquanto não origem - o que ela chama de "ruptura na história" que era ao mesmo tempo uma ruptura no Dasein -, o afrodescendente lida com uma identidade individual e coletiva fragmentada. Para Frantz Fanon (1981, p. 185), a experiência do ser-estar intersticial no meio daquilo que Paul Gilroy (2001, p. 260) chama de "raízes e rotas" produz "indivíduos sem âncora, sem horizonte, sem cor [...] e raízes - uma raça de anjos". É nessa história vivida pelos negros, mas muitas 
vezes escrita por outros, que residem os traços (in)visíveis do que Carole Boyce-Davies (1994, p. 151) chama de "subjetividade migratória" dos negros pan-americanos ${ }^{5}$. Esta subjetividade criada e perpetuada pela experiência do deslocamento leva, segundo Marlene Nourbese Philip (1997, p. 58), "muitas vezes, se não sempre a uma disjunção na psique" e a diversas formas de marginalidade: uma entre-condição de distanciamento e interioridade que, para poetas e escritores, pode ser "uma fonte de intensa criatividade" e "tensão" que lhes permite encarar a realidade de seus múltiplos lados. A condição intervalar do Dasein diaspórico - a constante migração entre o cá e o lá, o que Glissant (1997b, p. 211) chama de "enraizamento" e "errância" - faz com que os sujeitos definam a sua identidade e posição como sendo localizadas entre diferentes locais geográficos e sistemas significantes ${ }^{6}$. Profundamente arraigada na história da escravidão transatlântica, no imperialismo e (neo)colonialismo, a migração tem colocado os afrodescendentes perante uma mudança constante de atitudes, costumes e pontos de vista. A performance de diferentes locais e posições identitárias, portanto, significa uma existência intervalar caracterizada por identidades e relações fluidas e dinâmicas.

O termo que talvez melhor descreva este Dasein dinâmico - a desterritorialização - é um conceito ambivalente: é um duplo signo de perda e sofrimento, assim como de potencialização que aloja a reterritorialização, ou seja, a capacidade de transformação enquanto oportunidade de escoIher novas posições de sujeito e formas de vida. Esta ambivalência caracteriza a escrita afro-diaspórica no sentido de a desterritorialização da migração constituir um lugar de alienação e reconexão - lugar este, não somente em termos geográficos, históricos e intersubjetivos, mas também em termos de posição de classe, raça, sexualidade e gênero. Ao confrontar o indivíduo com a natureza plural e contraditória de identidade, a luta de identificação não leva à livre mobilidade, mas à passagem temporária de limites impostos. Ser afro-brasileiro, afro-caribenho, afro-americano, afrocanadense, portanto, sempre tem significado uma dança sobre o hífen e tem implicado diversas formas de "dupla-consciência". Na sua definição de "dupla-consciência”, Du Bois (1961, p. 16-17) descreve o impacto negativo

5 Em 1941, Richard Wright (1969, p. 143) descreveu a subjetividade afro-americana da seguinte forma: "Uma sensação de constante transformação introduziu-se furtivamente nas nossas vidas, determinando as nossas personalidades como uma lei de vida". espacial, manifesta-se também em termos raciais, étnicos, sociais e culturais.

16 Número temático: Literatura, cultura e memória negra. A Cor das Letras - UEFS, n. 12, 2011 
que o color line tem sobre a subjetividade, identidade e dignidade do afroamericano que vê a si mesmo e o mundo pelos olhos do outro. Este dualismo, enquanto dicotomia cultural implica um conflito psicológico, um self dilacerado como resultado da internalização da imagem do negro, o outro (simultaneamente abjeto e desejado) construído pelo discurso dominante. O split self também pode ser resultado da experiência traumática. Segundo Kirmayer (1996, p. 173-98), a duplicação do eu, um que se lembra do horror vivido e outro que o reprime, é uma característica freqüente nas histórias dos sobreviventes e reflete a disjunção entre o eu do trauma e o eu que se imagina fora deste. Estes dois eus representam mundos diferentes, mas são ligados pela continuidade da dor individual e da memória coletiva.

A análise da condição e tensão desta duplicação - o colapso e o renascimento da identidade negra - na interface das raízes e rotas que constituem o espaço da diáspora negra, deveria ser um dos principais objetivos da análise comparativa das literaturas negras. Soysal (2002, p. 138) tem defendido que a diáspora pode ser vista como "uma extensão do modelo do Estado-nação", no sentido de ela "constituir outridade nas [...] nações e etnicidades". Para poder analisar a representação desta outridade, isto é, a dinâmica da (não) pertença cultural, a identidade fractal, cuja natureza transculturada é constituída de múltiplos sistemas significantes, deveria ser o enfoque analítico. Neste sentido, é importante examinar como os autores afrodescendentes desenvolvem concepções de coesão e inteireza a partir das ruínas identitárias e culturais da história negra com o objetivo de revelar e problematizar os interstícios da vida e a vida nos interstícios dos afrodescendentes pan-americanos. Quais são os mecanismos e características deste ato mnemônico-estético de recuperação? Se a tentativa literária da descolonização do self significa necessariamente criar um novo lar na linguagem - a reconstrução do equilíbrio quebrado entre o self e o mundo -, então é pertinente problematizar a natureza dos diversos tipos de mímica discursiva que proporcionam este $\operatorname{lar}^{7}$.

Resumindo as idéias acima desenvolvidas, defende-se que a comparação analítica das literaturas afro-diaspóricas focalize a relação entre a geografia (paisagem/natureza/lugar/espaço/terra) e a episteme cultural (ethos/cosmovisão/identidade) dentro de um processo histórico com o objetivo de contribuir ao entendimento das relações (trans)culturais e (trans)nacionais dos grupos e comunidades afrodescendentes.

7 Criar um lar na linguagem é sempre uma reafirmação do signo como lugar de luta sobre autoridade semântica e social (ver Hitchcock, 1993). 


\section{MEMÓRIA}

Neste processo, a memória - compreendida como complexo processo de rememorização e esquecimento que caracteriza a relação entre as experiências pessoais e as historias compartilhadas de comunidades e seus modos de transmissão - é a transportadora da identidade diaspórica. Não existe diáspora sem memória: esquecer as conexões translocais diaspóricas significaria a última dispersão da identidade diaspórica. A memória diaspórica tem raízes em lugares; ela é situada num lugar, mas ao transcendê-lo não é limitada a este lugar. Ela tece fios de continuidade performativa dos quais muitos não têm conexão com a terra natal. Desta forma, a memória transcende a lógica da dispersão e volta terrestre e emerge como fonte da identidade diaspórica: a memória mais do que o território é a base da formação identitária em culturas diaspóricas como a dos afrodescendentes, onde, segundo Fortier (2005, p. 184) “o território é descentrado e explodido em múltiplos cenários".

Neste sentido, deveria se mapear a poética mnemônica dos textos problematizando tanto o corpo e a mente dos personagens, o status liminar entre pessoa e propriedade, como lugares de luta sobre o espaço social heterotópico quanto à complexa relação entre os sujeitos e seu ambiente no processo histórico. Este mapeamento nos confronta com três tipos de deslocamento entrelaçados: o deslocamento geográfico, físico e epistêmico do sujeito afrodescendente e o deslocamento de sua memória. Embora que toda memória seja caracterizada por movimento e mobilidade, isto é, um processo de deslocamento per se, o holocausto negro tinge esta memória com tons e sons traumáticos. Cada forma de memória - a memória individual de experiências pessoais, a memória coletiva de uma comunidade/tribo/nação ou a "pós-memória" (Hirsch, 1999) que atravessa gerações e etnias - depende de re-articulações. Conteúdos mnemônicos são constantemente reinventados. Em outras palavras, o deslocamento mnemônico significa associação metonímica e deslizamento semântico. Modelada pelas responsabilidades de dar testemunha como também pelas forças da amnésia e esquecimento normalizantes e por todas as formas de interesses políticos, a memória é um processo performativo, um "processo de conexão" (BAL, 1999, p. vii), ou segundo Huyssen (1995, p. 3), uma "recherche" cujo status temporal é sempre o presente. Visto desta perspectiva, a relação entre diáspora e memória é problemática e ambivalente: a memória é a condição e o limite necessário das identidades diaspóricas. Esta ambiguida- 
de levanta algumas questões importantes para a análise da consciência interior dos afrodescendentes como, por exemplo: quais as implicações políticas e éticas da adaptação das memórias do holocausto negro por pessoas que não têm uma conexão pessoal ou familiar com ele, mas as empregam como uma forma do discurso diaspórico? Como a memória individual, a memória coletiva e a pós-memória são ligadas no processo de transmitir o holocausto negro? E talvez mais urgente: quais as perspectivas políticas e culturais concretas de um diálogo entre as diversas memórias da diáspora negra?

Estas perguntas conotam uma das questões principais dos estudos afro-diaspóricos: Como é que a escrita negra lida com a perda e as diversas formas de violência como efeito do holocausto? Em Afro-América: Diálogos Literários na Diáspora Negra das Américas problematizo a escrita negra enquanto transescrita que, semelhante às práticas de cura de trauma, atravessa o luto na tentativa de trabalhar a perda e a ausência. A base desta hipótese é Sigmund Freud que em seu ensaio "Mourning and Melancholia" descreve o luto como o trabalho normal do inconsciente de desprender o ego de um objeto de valor psíquico significante que se perdeu: o processo que exige do ego que encare a realidade da perda. A dor de luto resulta do conflito entre a ligação do ego ao objeto perdido (devido ao encadeamento da libido com este objeto) e a realidade de que o objeto não existe mais. Rituais de luto que atribuem valor simbólico à perda facilitam a percepção da realidade da perda por parte do ego. Considero a teorização de Freud as ideias sobre o luto individual que traduzo para uma análise do luto cultural - útil para pensar sobre a relação entre a diáspora negra e a narração da sua história traumática. Neste sentido, a arte negra (e especialmente a literatura e a crítica literária) deveria ser considerada um dos meios cruciais de work through a perda enquanto problema de ausência - a ausência de totalidade, inteireza e/ou integração cultural mesmo antes da história traumática da escravização. Seguindo Freud, entendo work through como processo de lidar com esta perda, atravessá-la trabalhando, ou seja, revelar, examinar, problematizar e assim reconhecer a implicação numa história traumática cujo impacto é tanto latente quando visivelmente concreto. Não significa a recuperação utópica de uma cultura negra porque $a$ cultura inteira e original não existe. Significa, segundo Dominick LaCapra (1994, p. 200), "a reconstrução de vidas e a elaboração de uma historiografia crítica" pelo processo de "comparação de experiências e [...] reconstrução de contextos mais amplos que ajudam informar e talvez transformar a experiência". O 
apagamento do ancestral mediante o genocídio, o assassinato, a escravidão e a distorção da memória cultural é precisamente o trauma que precisa ser atravessado/trabalhado, ou melhor, perlaborado para uma reconstrução da episteme cultural. Em seguida será melhor elaborada esta relação entre a episteme cultural e a geografia.

\section{GEOGRAFIA E EPISTEME CULTURAL}

O termo "lugar" pode ser definido de maneira geográfica, ambiental, fenomenológica (ao ligar "corpo" e "lugar") e genealógica (ao ligar "ancestralidade" com "território"), em termos de expansão de império, urbanização e diminuição da natureza virgem, entre outros. Se segundo Henri Lefebvre (1974) os espaços são percebidos, concebidos e vividos, ou seja, tanto reais quanto imaginados e segundo Claude Raffestin (1980) a territorialidade é um tipo especifico de espaço delimitado pelo agenciamento dos personagens, então alego que a demarcação do espaço (com seus lugares) resulta tanto de medições e mapeamentos cartográficos quanto do sistema semiótico de linguagem e suas imagens articuladas. Para Ashcroft (2001, p. 156) "o lugar é um resultado de habitação, uma consequência dos modos como as pessoas vivem num espaço". Por outro lado, a maneira como pessoas habitam um lugar - seu imaginário, episteme cultural, língua, gestos, maneira de falar e vestir, etc. - é determinada por este lugar: o que é verdade/realidade num lugar e para um determinado grupo necessariamente não o é para outro. As particularidades do espaço constituem tanto o meio como o modo de nossa conscientização, ou seja, o espaço torna-se, simultaneamente, a forma das experiências vividas e imagem de seus conteúdos. Isso significa que pertencer a um lugar é determinado menos pelo que se possui em termos de propriedade (terreno, casa, etc.), do que pela relação entre a memória fragmentada e seletiva (sempre funcionando, para utilizar as palavras de Patrick Chamoiseau, em termos de "rupturas de tempo, lugares, tons e maneiras", 1986, p. 247) e a experiência vivida. Com base neste duplo sentido de lugar como entidade geográfica e produção sociocultural argumento que qualquer análise espacial deve examinar seu significado intrínseco e extrínseco, ou seja, seus próprios vetores como também as ramificações socioculturais e político-econômicas nas quais "raça", "etnia", "gênero", "idade" e "classe", entre outros vetores sociais contribuem para a constituição da experiência ambiental: como, em outras palavras, as histórias "naturais" são profundamente enraizadas em si mesmas e ao mesmo tempo no processo local e global das histórias mundiais.

20 Número temático: Literatura, cultura e memória negra. A Cor das Letras - UEFS, n. 12, 2011 
Ao enfatizar a produção da história no processo (pós-/neo)colonial do remapeamento mundial (Wallerstein, 1991) os estudos pós-coloniais têm utilizado o conceito de "lugar" para problematizar narrativas temporais de progresso impostas por poderes coloniais. Neste sentido, o lugar codifica o tempo sugerindo que as histórias encravadas na terra e no mar sempre têm providenciado metodologias vitais e dinâmicas para a compreensão do impacto transformativo do império e as epistemologias anticoloniais que este tenta negar e suprimir. A historização tem sido um dos meios primários dos estudos pós-coloniais e como Edward Said e Frantz Fanon, entre outros, enfatizaram nas suas obras, ela é crucial para o nosso entendimento do espaço. Assim, ao utilizar um modelo histórico de ecologia e uma epistemologia de espaço e tempo na análise literária é necessário engajar um dialogo com a paisagem/natureza. Este diálogo histórico é necessário porque o processo de desvincular a natureza da história ajudou mistificar as histórias coloniais de migração forçada, sofrimento e violência humana. Como é amplamente documentado nas criações literárias afrodescendentes, a terra e o mar são participantes neste processo histórico em vez de simples circunstantes/espectadores ${ }^{8}$, e os escritores nos fazem lembrar que o tempo acumula (e não passa) através de uma biota relacional, cujos elementos integrantes se constituem por um valor interior (e não um atribuído exteriormente). O passado continua existindo no presente não porque é posto no papel - isto significaria sua ausência na presença das letras -, mas por ser inscrito nas mentes e nos corpos dos diversos elementos da biota. Neste sentido, a análise literária de textos escritos por autores afrodescendentes deveria focaliza o que Edward Soja $(1989$, p. 7) chama a "geografia afetiva", ou seja, "a concretização das relações sociais embutidas na espacialidade" com o objetivo de problematizar o que o mesmo estudioso descreveu com o termo "geografias injustas" (2009): como a natureza e a cultura em suas relações complexamente entrelaçadas são embutidas em desenvolvimentos geograficamente desiguais. A geografia (paisagem, natureza, lugar, espaço, terra), portanto, tem que ser reconceitualizada como socialmente produzida mediante relações de dependência e domínio (relações de poder); relações estabelecidas de maneira social e hierárquica entre o aqui e o lá, o local e o global do espaço diaspórico.

8 O poeta afro-cubano Nicolas Guillén inclui o céu, ao lado da terra e do mar, enquanto participante testemunhal: "Hay que aprender a recordar / lo que las nubes no pueden olvidar [...] i Duro recuerdo recordar / lo que las nubes no / pueden olvidar / por el camino de la mar!" (Guillén, 1980). 
São os processos de memorização e rememorização, tanto individuais e coletivas em e entre etnias, que tecem as histórias enquanto espaço (diaspórico) que liga os lugares. Neste processo, o enfoque analítico deveria cair sobre a relação entre a episteme cultural (ethos e cosmovisão) e sua determinação pela rede de múltiplas relações, práticas e formas de poder existentes nos lugares e espaços nos quais a trama se desenvolve. $O$ meio ambiente não é mais limitado ao palco sobre o qual a trama se desenvolve; tampouco as atitudes do autor e dos personagens sobre o meio ambiente são limitadas ao desenvolvimento narrativo. São vistas como característica fundamental do horizonte ideológico da obra literária. "As paisagens", alega Simon Schama em Landscape and Memory (1996, p. 9), "que supomos livres de nossa cultura podem tornar-se, depois de um processo analítico [...] seu produto". A opinião que a cultura enquanto produto humano deve ser separada da natureza evita o fato que a cultura humana reside no mundo natural e que a nossa existência depende dos processos deste. As pessoas e a terra são enredadas num ser unificado e mutuamente recíproco; o ser e a história da terra são inseparáveis do ser e da história das pessoas e vice versa. De onde vem a palavra "humano"? Da palavra-raiz "humus". Isto significa que a palavra "humano" carrega literalmente dentro de si o húmus de onde surgimos e voltamos. Somos, portanto ligados à terra e às outras formas de vida na terra. Tratar estas outras formas sem respeito resulta da não compreensão desta relação. Seguindo Walter Benjamin (1992), que define a alegoria barroca em termos de uma relação dialética em que uma linha, em vez de ser paralela é o traço de outra, considero a relação entre a história/experiência humana e a natureza um dos melhores exemplos desta dialética alegórica, ou seja, a natureza como registro da história/experiência/decadência humana.

Fredric Jameson (1992, p. 64), com base no argumento de Northrop Frye que a literatura é uma forma mais fraca do mito ou estágio posterior do ritual, alegou que "toda literatura deve ser permeada por aquilo a que chamamos de inconsciente político, que toda literatura tem que ser lida como uma meditação simbólica sobre o destino da comunidade". Neste sentido, e até de forma sutil ligado com este inconsciente político cuja base é radicada nas relações humanas caracterizadas por domínio, subalternização e resistência, argumento que se pode falar de um inconsciente ecológico que imbui a relação entre seres humanos e seu ambiente. Se para Jameson o inconsciente político é a ausente (e ao mesmo tempo presente porque desejada) revolução cultural que transformaria a hegemonia injusta do sistema político em democracia justa, defino o inconsciente ecológico

22 Número temático: Literatura, cultura e memória negra. A Cor das Letras - UEFS, n. 12, 2011 
como ausente (e ao mesmo tempo presente porque desejada) revolução ecológica que constituiria uma mudança de visão em relação à biota.

Em terras colonizadas, coma nas Américas por exemplo, a brutalização das pessoas é ligada à brutalização do espaço e estas brutalizações são enraizadas no passado: o genocídio de tribos indígenas, a escravidão e o sistema de plantação e as várias formas de exploração da natureza, entre outros, caracterizaram as diferentes fases e processos de colonização e ainda continuam ter um impacto sobre o pensamento e o agir das pessoas não somente em termos de como as pessoas se relacionam e tratam os diversos outros (penso, por exemplo, no racismo e no sexismo em suas formas tanto ideológicas quanto instintuais), mas de como as imagens destes eventos traumáticos perseguem estes pensamentos e agenciamentos. $A$ representação do espaço ${ }^{9}$ é simbolizada por uma natureza nutrida pelos corpos violados da história colonial, um engajamento literal com o que o poeta caribenho Wilson Harris (1981, p. 90) chama "o fóssil vivo de culturas enterradas". Esta dupla brutalização dos seres humanos e da geografia (terra, paisagem, natureza, espaço, lugar) é interligada e constitui de diversas maneiras o inconsciente sociocultural e ecológico da experiência panamericana - o fantasma deste holocausto recalcado que volta em resposta à Verleugnung (negação) fazendo sentir sua presença tanto no nível da enunciação quanto no da experiência vivida.

Qual é o papel da literatura neste processo? Gostaria de ligar esta pergunta com duas outras: qual é o papel da literatura no mundo? Qual a contribuição da literatura e dos estudos literários em ligação com a ecocrítica pós-colonial para a compreensão do mundo e da realidade? A literatura é um dos meios privilegiados de construção mitológica coletiva. Como encruzilhada onde discursos e visões em conflito e competição se encontram e entram num equilíbrio muitas vezes precário e contraditório, a literatura constitui um lugar onde diferentes valores, mitos, histórias e traduções estão sendo negociados. É por meio da literatura enquanto espaço mnemônico que escritores recriam os mitos necessários para se enraizar como sujeitos autóctones. A reapropriação do espaço via memória possibilita a colocação do sujeito na sua própria história. A renomeação do seu lugar e da sua história significa reconstruir sua identidade, tomar posse de sua cultura; significa, em última análise, resistir a uma violência epistêmica que,

9 Espaço nacional que, segundo o critico Antonio Cornejo Polar (2000, p. 147) é caracterizado por "heterogeneidade conflituosa" como resultado da colonização imperialista. Para ele, as nações latino-americanas são "traumaticamente desmembradas e cindidas". 
nas suas diversas formas e práticas continua até o presente. Desta forma, a literatura molda ideias, crenças e ideais históricos e éticos contribuindo para a constituição da episteme cultural coletiva. Ao analisar de maneira comparativa e interdisciplinar as semelhanças e diferenças que caracterizam a interface geografia/episteme cultural na escrita negra ganha se insights dos diversos tipos de identidade cultural que constituem a diáspora afrodescendente. Gostaria de traçar quatro tipos de insight que surgem neste processo: a) Insights sobre assunções antropocêntricas: a relação entre o senso de lugar e a consciência ética (reflexão ética); b) Insights sobre mimese e referência com respeito ao lugar habitado (reflexão hermenêutica); c) Insights sobre a episteme cultural/a experiência humana num dado lugar e processo histórico (reflexão ontológica/identitária); d) Insights sobre a relação entre a escrita, a vida e práticas pedagógicas (reflexão ideológica).

Neste sentido, se considerarmos que as literaturas afrodescendentes constituem repositórios complexos das representações das experiências humanas é plausível que por meio de abordagens adequadas a teoria literária consegue enfocar semelhanças e diferenças culturais de maneira única. O enfoque na experiência vivenciada que analisa as relações entre seres humanos e outras formas de vida que compõem o ecossistema, faz surgir paradigmas teóricos que encapsulam interconexões conceptuais e atuais em termos de identidade cultural no nível local (regional/nacional) e global (transregional/nacional). Dado o fato de que um dos problemas principais a ser resolvido no século XXI é a coexistência de culturas radicalmente diferentes e de que a literatura revela e problematiza os paradoxos e aporias da vida mediante as suas representações argumento que a essência ética da teoria literária é de constituir, junto com o seu objeto de estudo, a literatura, uma ciência da/para a vida, ou como diria Édouard Glissant, uma ciência $\mathrm{da} /$ para le tout-monde, le chaos-monde, ou ainda, la totalité monde: as inter-relações nos lugares e entre diversos lugares do mundo; relações estas constituídas por processos de crioulização. Neste sentido, tanto os lugares quanto as relações "transformam-se uns nos outros sem fim" (GLISSANT, 1996, p. 275). Para Glissant, a abertura de fronteiras para espaços fronteiriços e raízes para rotas/rizomas/fluxos nas críticas e pensamentos pós-modernos é uma mudança de transcendência para transversalida$\mathrm{de}^{10}$. Segundo Glissant (2002, p. 71-72), deveríamos suplementar o pensamento-raiz com um pensamento-rizoma ou arquipélago: “En el en-

\footnotetext{
10 O sistema sincrônico das forças convergentes que constituem a identidade antilhana.
}

24 Número temático: Literatura, cultura e memória negra. A Cor das Letras - UEFS, n. 12, 2011 
cuentro de culturas del mundo, debe asistirnos el poder imaginario para concebir todas las culturas como factores que tienden, al mismo tiempo, a la unidad y la diversidad libertadora". Entender o mundo enquanto "chaosmonde" ou "tout-monde" constituído por fluxos erráticos entre dobras fractais $^{11}$ significa, em última análise, não poder/querer compreendê-lo totalmente. O raciocínio glissantiano levanta um ponto raramente tocado por críticos: a incomensurabilidade das relações interculturais que reside no seu caráter transcultural. Glissant, neste sentido, fala de "opacité". A opacidade das relações interculturais é o sedimento que se acumula no processo da inter-relação cultural. Como tal contribui para a imprevisibilidade e não linearidade (o caos) destas relações ${ }^{12}$. Este sedimento é a base insondável e fértil da experiência intersubjetiva/intercultural que somente pode ser sentido em vez de racionalmente ser compreendido. A opacidade também pode ser utilizada como desvio deliberado na luta da resistência cultural. Como tal, estabelece um padrão de camuflagem, distorção, deslocamento e subterfúgio no processo de significação. A crioulização cultural, segundo Glissant, visa a substituir a dominação hierarquizante por uma convivência em processo para que a diferença enquanto separação possa ceder à diversidade como relação dinâmica. Para Glissant (1997a, p. 239), "a multienergia das crioulizações [...] reativa esta dilatação vertiginosa onde se desfazem não as diferenças, mas os sofrimentos antigos nascidos da diferença". O caos-mundo glissantiano é o mundo real: um mundo em processo onde a imaginação suplementa a razão, o opaco encanta o claro, o errante ilumina o sedentário, o ser humano se redescobre no mundo dos animais e das plantas; um mundo, enfim, onde o amor e o respeito vencem qualquer tipo de agressão e violência. O papel da literatura, portanto, é fundamental no sentido de "contribuir, pelos poderes da imaginação, a fazer levantar a rede, o rizoma das identidades abertas que falam e escutam entre si" (GLISSANT, 1997a, p. 248) e neste processo revelar a natureza não sincrônica, não linear, acidental e indeterminada da realidade; realidade esta onde o processo de relacionamento é mantido instável e dinâmico pela opacidade.

11 Fractal no sentido de cada dobra, identidade ou fragmento cultural ser pensado em relação aos seus múltiplos outros.

12 Em Glissant, portanto, o conceito de caos não significa desordem, mas é baseado na ciência do caos mediante a qual se problematiza estruturas profundas na física e natureza. No mundo-caos, portanto, nem a ordem nem a desordem dominam, mas o sinuoso desdobramento das forças interativas. 
O critico Leo Spitzer (1993, p. 179) definiu os estudos literários como "a ciência que tem como objetivo compreender o ser humano na sua expressão em palavras e criações lingüísticas". Para Erich Auerbach (1969, p. 17), falando sobre a filologia que Goethe tinha cunhado Weltliteratur, a ciência literária deve "designar o lugar do ser humano no universo". Já para Glissant, o objetivo da teoria da literatura comparada deve ser a reativação da "estética da terra". Em Poétique de la relation, Glissant (1997b, p. 150151) argumenta que este fazer poético nos possa ajudar a mudar o "pesadelo" que atualmente estamos vivendo. Mas como conseguir restabelecer esta "conexão estética da terra", pergunta ele, num contexto cultural de produção e consumo material desenfreado e seu efeito de fragmentação, alienação, miséria e violência humana? E responde: por meio de uma "estética de interrupção, ruptura e conexão" que envolve a imaginação. Em Traité du tout-monde, Glissant (1997a, p. 119) afirma que, ao contrário da ciência, "a escritura nos leva às intuições imprevisíveis, nos faz descobrir os constantes escondidos do mundo". É mediante o imaginário, o seu prolongamento "por uma explosão infinita" (GLISSANT, 1997a, p. 18), que se pode descobrir novas possibilidades e vencer os obstáculos que impedem o ser humano de se realizar de maneira digna e justa.

Como podemos traduzir este raciocínio glissantiano para a literatura comparada da diáspora negra? Gostaria de sugerir a aplicação do eixo analítico constituído pelo inconsciente político, cultural e ecológico dentro da interdisciplinaridade entre a teoria pós-colonial e a ecocrítica.

Como crítica ao império da história e cultura européia e, por extensão, do Ocidente a teoria pós-colonial revela e problematiza: a) a durabilidade do poder colonial desde o passado ao presente; b) como surgem neste processo novas formas e práticas de domínio e subalternização. Com o enfoque nas relações de poder, nas posições do sujeito (agenciamento), nas diásporas e nos deslocamentos criados por meio do colonialismo/imperialismo/globalização a teoria pós-colonial negligenciou questões com respeito à interface cultura/natureza ${ }^{13}$.

A ecocrítica, dentro dos estudos literários, tem se desenvolvida em três direções fundamentais: a) no sentido de uma metodologia sociológica

13 O termo pós-colonial é ambíguo e muito questionado. Para dois excelentes ensaios que problematizam o termo, ver Ella Shohat (2000) e Stuart Hall (2003). Sobre o póscolonialismo e a pós-colonialidade, ver, entre outros, Ashcroft, et.al. (1989), Bhabha (1998), Young (1995, 2003), Lionnet (1995), Childs (1997), Ghandi (1998), Loomba (1998, 2005), Moura (1999), Spivak (1999), Brydon (2000), Bonnici (2000), Pryston (2002) e Mignolo (2003).

26 Número temático: Literatura, cultura e memória negra. A Cor das Letras - UEFS, n. 12, 2011 
interdisciplinar que examina a relação entre personagens e a natureza, enfocando a consciência ecológica destes com relação a questões ecológicas locais e globais; b) no sentido de uma metodologia cultural-antropológica interdisciplinar que problematiza a alienação e reificação do ser humano enquanto resultado da dominação da natureza dentro do projeto civilizatório moderno; c) no sentido de uma metodologia ética interdisciplinar, cujo objetivo é a revisão do sistema de valores culturais antropocêntricos como base de uma coexistência planetária inter-relacionada. $O$ que liga estas três abordagens é a compreensão da natureza enquanto entidade físicomaterial e como entidade social ativamente envolvida na dinâmica das construções culturais ${ }^{14}$.

É preciso aprofundar o diálogo entre os estudos pós-coloniais e ecológicos já que a separação entre a história do império e pensamentos ecológicos contribui para a constituição de um discurso de orientalismo verde que ofusca um dos pilares básicos do colonialismo, a saber: a exploração da natureza. Gostaria de delinear brevemente quatro áreas de contato entre os estudos pós-coloniais e ecológicos: a) Uma moldura ecológica é de suma importância para compreender como a geografia (paisagem, natureza, lugar, espaço, terra) foi e continua sendo alterada de maneira radical pelo neocolonialismo do capitalismo tardio, processo este que inclui o uso das matérias primas, exploração de mão de obra e soberania, entre outros questões cruciais para os movimentos de independência e suas literaturas constitutivas. Ao examinar epistemologias de espaço/natureza (pré-)coloniais, os estudos pós-coloniais devem explorar como estas sobrevivem e foram transformadas e traduzidas por meio de formas e práticas narrativas; b) Os dualismos iluministas de cultura/natureza, branco/negro e masculino/feminino, entre outros, foram constituídos mediante processos coloniais e críticos pós-coloniais e ecofeministas têm se ocupado há muito tempo com o desvencilhamento das relações de poder hierárquicas que se escondem atrás e agem por meio destes binarismos; c) A interrogação ecocrítica do antropocentrismo e o enfoque sociocultural do pós-colonialismo são interdependentes já que estes assuntos afetam as diversas espécies e esferas da biota; d) Questões de agenciamento e representação do sujeito su-

14 Para a relação entre literatura, pós-colonialismo e ecocrítica, ver entre outros, Glotfelty (1996), Buell (1995, 2001, 2005, 2007), Plumwood (2001, 2003), Philips (2003), Huggan (2004, 2010), Curtin (2005), French (2005) Garrard (2006), Cilano e DeLoughrey (2007), Marzec (2007), Vital e Erney (2007) Walter e Ferreira (2010), Wright (2010) e DeLoughrey e Handley (2011). 
balterno, além de revelar formas e práticas de domínio e resistência, implicam em diversos aspectos da episteme cultural - a maneira como o indivíduo vê a sua posição de sujeito numa dada sociedade (ethos) e como, a partir desta posição, ele/ela vê o mundo (cosmovisão) - , e seu efeito no processo da produção da subjetividade e identidade individual e coletiva. Neste processo, uma análise pós-colonial ecologista eleva ao primeiro plano os modos como a narrativa no seu nível discursivo e temático traduz (e assim produz) alteridade e diferença cultural ${ }^{15}$. A noção da diferença cultural como processo transcultural de compartilhamento implica na confluência de diferenças sem a sublimação dos seus diversos elementos num todo coerente: um reconhecimento da sobreposição e/ou justaposição dos diversos outros constituindo o self. Neste sentido, num contexto pós-colonial a identidade e a cultura envolvem diferenças mutuamente refratadas e muitas vezes deslocadas na dança esquizofrênica da cultura e do imperialismo. Gostaria de afirmar que isto é a base a partir da qual se deve pensar a alteridade/diferença cultural entre o local e o global num contexto póscolonial.

A transformação ecológica é baseada numa transformação das relações humanas com as espécies não humanas. Ao recuperar a conexão com a natureza podemos explorar possibilidades de renovação social, cultural e psicológica. Uma re-imaginação e reconfiguração do lugar humano na natureza fazem necessária uma interrogação da categoria do humano e como a construção dos seres humanos contra a natureza - com a hierarquização das formas de vida que esta construção implica - foi e continua sendo implícita na exploração capitalista e racista desde o tempo da conquista imperial até hoje em dia. Em outras palavras, dever-se-ia problematizar o que o filósofo Deane Curtin chama de "racismo ambiental", isto é "a conexão, em teoria e prática, entre raça e ambiente de forma que a opressão de um é ligada e sustenta a opressão de outro" (2005, p. 145). O racismo ambiental é um fenômeno sociológico exemplificado no tratamento ecologi-

15 O cerne deste enfoque é a questão da ideologia: a organização de práticas significantes materiais que constituem subjetividades - entendidas como posições de inteligibilidade, ou seja, os modos de saber necessários pela reprodução de disposições/ordens sociais existentes (como, por exemplo, a divisão patriarcal do real em termos de gênero; os modos de produção/consumo em termos de capitalismo; a necessidade/justificação de processos colonizadores) - e produzem as relações vividas mediante as quais os indivíduos são ligados - de maneira hegemônica ou contra-hegemônica - às relações de produção e distribuição de poder dominantes (e às relações de exploração daí resultantes) numa formação social especifica num dado momento histórico.

28 Número temático: Literatura, cultura e memória negra. A Cor das Letras - UEFS, n. 12, 2011 
camente discriminatório de povos socialmente marginalizados ou economicamente discriminados. É uma forma extrema do que Val Plumwood (2001, p. 4) chama de "centrismo hegemônico": a perspectiva autoprivilegiada como base do racismo, sexismo, colonialismo e imperialismo; formas de domínio entrelaçadas que tenham sido convocadas historicamente com o objetivo de explorar a natureza e ao mesmo tempo minimizar pretensões não humanas a uma natureza compartilhada. Neste processo, não se deve esquecer, como Plumwood (2003, p. 53) assinala, que a definição ocidental da humanidade sempre dependeu e continua depender da presença do não humano como incivilizado e animalesco. A justificação de processos de invasão/colonização/dominação procedeu desta base antropomórfica e racista.

Para Glissant o início de qualquer análise cultural tem que focalizar aquilo que gera as nossas culturas, o dinamismo dos seus conteúdos interrelacionados. Gostaria de concluir, alegando que la poétique de la relation glissantiana focaliza este dinamismo transcultural através de uma escritura em busca de respostas à questão da outridade/outrização e da dupla maldição que constitui a base da fundação das sociedades nas Américas: a brutalização do ser humano relacionada à brutalização do ambiente desde o passado ao presente. Neste sentido, a "estética da terra" glissantiana ao enfatizar que a terra e o habitante da terra são saturados por traumas de conquista liga o indivíduo, a comunidade e a terra no processo de criar história da não história (neo/pós-)colonial. Neste processo, Glissant espera que a literatura possa ensinar a força política da ecologia, ou seja, que a literatura possa traduzir a articulação radical da ecologia "da interdependência de todas as terras, do mundo inteiro" (1997a, p. 147). Para escritores afrodescendentes, entre outros, que viveram/vivem diversos tipos de (neo)colonização, portanto, é de suma importância trabalhar a relação entre o indivíduo e o espaço: quem tem sua história destruída, distorcida ou camuflada, busca esta história nos lugares do espaço onde seus antepassados viveram, ou seja, nos rios, bosques, nas montanhas, savanas, etc. O objetivo de liberar o futuro (esquecido) do passado no presente, aquela parte do passado que, segundo Walter Benjamin, ainda não se concretizou e, portanto, deve ser resgatada e problematizada, é de descobrir nas ruínas do passado as causas dos desastres e tanto a responsabilidade quanto a promessa de um presente e futuro melhor. 


\section{REFERÊNCIAS}

APPIAH, K. Anthony. In My Father's House: Africa in the Philosophy of Culture. New York: Oxford UP, 1992.

ASHCROFT, Bill. Post-Colonial Transformation. London: Routledge, 2001.

ASHCROFT, Bill; GRIFFITHS, Gareth; TIFFIN, Helen. (Org.). The Empire Writes Back: Theory and Practice in Post-Colonial Literatures. New York/London: Routledge, 1989.

AUERBACH, Erich. Philology and Weltliteratur. Centennial Review, v. 13, n. 1, p. 1-17, 1969.

AUGÉ, Marc. Non-Lieux. Introduction à une anthropologie de la surmodernité. Paris: Seuil, 1992.

BACHELARD, Gaston. The Poetics of Space. Trad. Marie Jolas. Boston: Beacon Press, 1969.

BAL, Mieke. Introduction. In: BAL, Mieke; CREWE, Jonathan; SPITZER, Leo. (Org.). Acts of Memory. Cultural Recall in the Present. Hanover/London: New England UP, 1999, p. vii-xvii.

BENÍTEZ-ROJO, Antonio. The Repeating Island: The Caribbean and the Postmodern Perspective. Durham: Duke UP, 1996.

BENJAMIN, Walter. The Origin of German Tragic Drama. London: NLB, 1992.

BONNICl, Thomas. O pós-colonialismo e a literatura. Maringá: Ed. da Universidade Estadual de Maringá, 2000.

BOURDIEU, Pierre. Coisas ditas. Trad. Cássia R. da Silveira; Denise M. Pegorin. São Paulo: Brasiliense, 2009.

BOURDIEU, Pierre. Outline of a Theory of Practice. Cambridge: Cambridge UP, 1977.

BOYCE DAVIES, Carole. Black Women, Writing and Identity. New York: Routledge, 1994.

BRAH, Avtar. Cartographies of Diaspora: Contesting Identities. London/New York: Routledge, 1996.

BRAND, Dionne. A Map to the Door of No Return. Notes to Belonging. Toronto: Vintage, 2002.

BRUBAKER, Rogers. The 'Diaspora' Diaspora. Ethnic and Racial Studies, v. 28, n. 1, p. 1-19, 2005.

BRYDON, Diana. Postcolonialism: Critical Concepts in Literary and Cultural Studies. London/NewYork: Routledge, 2000.

BUELL, Lawrence. Ecoglobalist Effects: The Emergence of U.S. Environmental Imagination on a Planetary Scale. In: DIMOCK, Wai Chee; BUELL, Lawrence. (Org.). Shades of the Planet: American Literature as World Literature. Princeton UP, 2007, p. 227-248.

BUELL, Lawrence. The Environmental Imagination: Thoreau, Nature Writing, and the Formation of American Culture. Cambridge: Harvard UP, 1995.

BUELL, Lawrence. The Future of Environmental Criticism: Environmental Crisis and Literary Imagination. Malden, MA: Blackwell, 2005.

BUELL, Lawrence. Writing for an Endangered World: Literature, Culture, and Environment in the U.S. and Beyond. London: Belknap Press, 2001.

CHAMOISEAU, Patrick. Chronique des sept misères. Paris: Gallimard, 1986. 
CHILDS, Peter; WILLIAMS, Patrick. An Introduction to Post-Colonial Theory. Harlow: Pearson Education, 1997.

CILANO, Cara; DELOUGHREY, Elizabeth. Against Authenticity: Global Knowledge and Postcolonial Ecocriticism. Interdisciplinary Studies in Literature and Environment (ISLE), v. 14, n. 1, p. 71-87, Summer 2007.

CLIFFORD, James. Routes: Travel and Translation in the Late Twentieth Century. Cambridge: Harvard UP, 1997.

CORNEJO-POLAR, Antonio. O condor voa: literatura e cultura latino-americanas. Org. Mario J. Valdés. Belo Horizonte: EdUFMG, 2000.

CURTIN, Deane W. Environmental Ethics for a Postcolonial World. Lanham: Rowman \& Littlefield, 2005.

DELOUGHREY, Elizabeth; HANDLEY, George. (Org.). Postcolonial Ecologies: Literatures of the Environment. New York: Oxford UP, 2011.

DU BOIS, W. E. B. The Souls of Black Folk. Greenwich, Conn.: Fawcett, 1961.

FANON, Frantz. Black Skin, White Masks. Trad. Charles L. Markmann. New York: Grove Press, 1967.

FANON, Frantz. Die Verdammten dieser Erde. Frankfurt: Suhrkamp, 1981.

FORTIER, Anne-Marie. Diaspora. In: ATKINSON, David, et. al. (Org.). Cultural Geography. A Critical Dictionary of Key Concepts. London e New York: I. B. Tauris, 2005, p. 182-187.

FRENCH, Jennifer L. Nature, Neo-Colonialism and the Latin American Regional Writers. Hanover: University Press of New England, 2005.

FREUD, Sigmund. Mourning and Melancholia. In: The Standard Edition of the Complete Psychological Works of Sigmund Freud, v. 14. Trad. James Stachey. London: The Hogarth Press and the Institute of Psycho-Analysis, 1973, p. 237-58.

GARRARD, Greg. Ecocrítica. Brasília: EdUNB, 2006.

GHANDI, Leela. Postcolonial Theory: A Critical Introduction. New York: Columbia UP, 1998.

GILROY, Paul. Against Race: Imagining Political Culture beyond the Color Line. Cambridge: Harvard UP, 2000.

GILROY, Paul. Diaspora and the Detours of Identity. In: WOODWARD, Kathryn. (Org.). Identity and Difference. London: Sage, 1997, p. 299-346.

GILROY, Paul. O Atlântico Negro: modernidade e dupla consciência. Trad. Cid Knipel Moreira. Rio de Janeiro: Ed. 34, 2001.

GLISSANT, Édouard. Faulkner, Mississippi. Paris: Gallimard, 1996.

GLISSANT, Édouard. Introdución a una poetica de lo diverso. Barcelona: Ediciones del Bronce, 2002.

GLISSANT, Édouard. Traité du Tout-Monde. Paris: Gallimard, 1997a.

GLISSANT, Édouard. Poetics of Relation. Ann Arbor: The University of Michigan Press, 1997b.

GLOTFELTY, Cheryll; FROMM, Harold. (Org.). The Ecocriticism Reader: Landmarks in Literary Ecology. Athens: University of Georgia Press, 1996. 
GUILLEN, Nicolás. Obra Poética, 1922-1958. Org. Angel Augier. Havana: Editorial Letras Cubanas, 1980.

HALL, Stuart. Cultural Identity and Diaspora. In: MIRZOEFF, Nicholas. (Org.). Diaspora and Visual Culture. London/New York: Routledge, 2000, p. 21-33.

HALL, Stuart. Culture, Community, Nation. Cultural Studies, n. 7, p. 349-63, 1993.

HALL, Stuart. Subjects in History: Making Diasporic Identities. In: LUBIANO, Wahneema. (Org.). The House That Race Built. New York: Vintage, 1998, p. 289-299.

HALL, Stuart. Quando foi o pós-colonial? Pensando no limite. In: SOVIK, Liv. (Org.). Da diáspora: identidades e mediações culturais. Belo Horizonte: Ed. UFMG, 2003, p. 101-128.

HARRIS, Joseph. Global Dimensions of the African Diaspora. Washington D.C.: Howard UP, 1993.

HARRIS, Wilson. Epilogue: Theatre of the Arts. In: DELOUGHREY, Elizabeth M.; GOSSON, Renée K.; HANDLEY, George B. (Org.). Caribbean Literature and the Environment: Between Nature and Culture. Charlottesville/London: University of Virginia Press, 2005, p. 261-268.

HARRIS, Wilson. Explorations: A Selection of Talks and Articles 1966-1981. Mundelstrap: Dangeroo Press, 1981.

HIRSCH, Marianne. Projected Memory: Holocaust Photographs in Personal and Public Fantasy". In: BAL, Mieke; CREWE, Jonathan; SPITZER, Leo. (Org.). Acts of Memory. Cultural Recall in the Present. Hanover/London: New England UP, 1999, p. 3-23.

HITCHCOCK, Peter. Dialogics of the Oppressed. Minneapolis/London: University of Minnesota Press, 1993.

HUGGAN, Graham. 'Greening' Postcolonialism: Ecocritical Perspectives. Modern Fiction Studies, v. 50, n. 3, p. 701-733, 2004.

HUGGAN, Graham; TIFIN, Helen. (Org.). Postcolonial Ecocriticism: Literature, Animals, Environment. New York/London: Routledge, 2010.

HUYSSEN, Andreas. Diaspora and Nation. In: BARONIAN, Marie-Aude; BESSER, Stephan; JANSEN, Yolande. (Org.). Figures of Displacement in Contemporary Literature, Arts and Politics. Amsterdam/New York: Rodopi, 2007, p. 81-96.

HUYSSEN, Andreas. Twilight Memories. Making Time in a Culture of Amnesia. London e New York: Routledge, 1995.

JAMESON, Fredric. O inconsciente político. A narrativa como ato socialmente simbólico. Trad. Valter L. Siqueira. São Paulo: Ática, 1992.

KIRMAYER, Lawrence J. Landscapes of Memory: Trauma, Narrative, and Dissociation. In: ANTZE, Paul; LAMBEK, Michael. (Org.). Tense Past. Cultural Essays in Trauma and Memory. New York: Routledge, 1996.

LACAPRA, Dominik. Representing the Holocaust: History, Theory, Trauma. Ithaca: Cornell UP, 1994.

LEFEBVRE, Henri. La production de l'espace. Paris: Anthropos, 1974.

LIONNET, Françoise. Postcolonial Representations: Women, Literature, Identity. Ithaca: Cornell UP, 1995.

LOOMBA, Ania. Colonialism/Postcolonialism. London: Routledge, 1998.

32 Número temático: Literatura, cultura e memória negra. A Cor das Letras - UEFS, n. 12, 2011 
LOOMBA, Ania et. al. (Org.). Postcolonial Studies and Beyond. Durham/London: Duke UP, 2005.

MARZEC, Robert. An Ecological and Postcolonial Study of Literature: From Daniel Defoe to Salmon Rushdie. New York: Palgrave, 2007.

MIGNOLO, Walter. Histórias locais/projetos globais: colonialidade, saberes subalternos $e$ pensamento liminar. Trad. Solange Ribeiro de Oliveira. Belo Horizonte: Ed. UFMG, 2003.

MOURA, Jean-Marc. Littératures francophones et théories postcoloniales. Paris: PUF, 1999.

PEEREN, Esther. Through the Lens of the Chronotope. Suggestions for a Spatio-Temporal Perspective on Diaspora. In: BARONIAN, Marie-Aude; BESSER, Stephan; JANSEN, Yolande. (Org.). Diaspora and Memory. Amsterdam/New York: Rodopi, 2007, p. 67-77.

PHILIP, Marlene Nourbese. A Genealogy of Resistance and Other Essays. Toronto: The Mercury Press, 1997.

PHILIPS, Dana. The Truth of Ecology: Nature, Culture, and Literature in America. Oxford: Oxford UP, 2003.

PLUMWOOD, Val. Decolonizing Relationships with Nature. In: ADAMS, William H.; MULLIGAN, Martin. (Org.). Decolonizing Nature: Strategies for Conservation in a PostColonial Era. London: Earthscan, 2003, p. 51-78.

PLUMWOOD, Val. Environmental Culture: The Ecological Crisis of Reason. London: Routledge, 2001.

PRYSTON, Angela. Cosmopolitismos periféricos: ensaios sobre modernidade, pósmodernidade e estudos culturais na América Latina. Recife: Bagaço, 2002.

RAFFESTIN, Claude. Pour une geographie du pouvoir. Paris: Librairies Techniques, 1980.

SAFRAN, Williams. Diasporas in Modern Societies: Myths of Homeland and Return. Diaspora. A Journal of Transnational Studies, v. 1, n. 1, p. 83-99, 1991.

SAID, Edward. Cultura e Imperialismo. Trad. Deane Bottmann. São Paulo: Cia. das Letras, 1995.

SAID, Edward. Orientalismo. Trad. Rosaura Eichenberg. São Paulo: Cia. do Bolso, 2007.

SCHAMA, Simon. Landscape and Memory. New York: Vintage, 1996.

SHEPPERSON, George. The African Diaspora - or The African Abroad. African Forum 2, p. 76-93, 1976.

SHEPPERSON, George. Pan-Africanism and 'pan-Africanism': Some Historical Notes. Phylon v. 23, n. 4, p. 346-58, 1962.

SHOHAT, Ella. Notes on the Postcolonial. In: AFZAL-KHAN, Fawzia; SESHADRI-CROOKS, Kalpana. (Org.). The Pre-Occupation of Postcolonial Studies. Durham: Duke UP, 2000, p. 126139.

SOJA, Edward. Postmodern Geografies: The Reassertion of Space in Critical Social Theory. London: Verso, 1989.

SOJA, Edward. Conferência de abertura na Postcolonial Translocations ASNEL/GNEL Conference, Münster, Alemanha, 2009. 
SOYSAL, Yasemin N. Citizenship and Identity: Living in Diasporas in Post-War Europe? In: HEDETOFT, UIf; HJORT, Mette. (Org.). The Postnational Self: Belonging and Identity. Minneapolis/London: University of Minnesota Press, 2002, p. 137-51.

SPITZER, Leo. Das Eigene und das Fremde: Über Philologie und Nationalsozialismus. Lendemains, v. 18, n. 69-70, p. 179-191, 1993.

SPIVAK, Gayatri Ch. A Critique of Postcolonial Reason: Toward a History of the Vanishing Present. Cambridge: Harvard UP, 1999.

WALLERSTEIN, Immanuel. Geopolitics and Geoculture: Essays on the Changing WorldSystem. Cambridge: Cambridge UP, 1991.

WALTER, Roland. Afro-América: diálogos literários na diáspora negra das Américas. Recife: Bagaço, 2009.

WALTER, Roland. The Ecological Unconscious in Multi-Ethnic Literature of the United States. Estudos Anglo-Americanos, n. 31-33, p. 185-202, 2007/2009.

WALTER, Roland; FERREIRA, Ermelinda. (Org.). Narrações da violência biótica. Recife: Ed. UFPE, 2010.

WRIGHT, Laura. Wilderness into Civilized Shapes: Reading the Postcolonial Environment. Athens: The University of Georgia Press, 2010.

WRIGHT, Richard. 12 Million Black Voices. New York: Arno Press and the New York Times, 1969.

YOUNG, Robert J. C. Colonial Desire: Hybridity in Theory, Culture and Race. London/New York: Routledge, 1995.

YOUNG, Robert J. C. Postcolonialism: A Very Short Introduction. New York: Oxford UP, 2003. 